\title{
A Study of Incidence of Pre-Eclampsia in Relation to Maternal Age
}

\author{
Ranjana Dhar \\ Assistant Professor of Physiology, Silchar Medical College, Silchar, Assam, India
}

\begin{abstract}
Background: - Pre-eclampsia is a serious complication of pregnancy and contributes significantly maternal as well as perinatal morbidity and mortality. So this study is done to find if there exists any relationship between maternal age and pre-eclampsia.
\end{abstract}

Aim:- To study what age group is more prone to development of pre-eclampsia in normal pregnancies.

Methodology:- 400 pre-eclamptic women in age group 18-42 years were included in the study. Cases are divided according to different age group.

Result:- Higher incidence of pre-eclampsia was observed in the age group 18-26 years followed by 35-42 years.

Discussion:- Age is found to be related to pre-eclampsia.

Conclusion:- From this study, this can be concluded that age less than 25 years and age greater than 35 years are more prone to development of pre-eclampsia.

Key Words :- Maternal age, pre-eclampsia, proteinuria, blood pressure.

\section{Introduction}

The glory of attaining motherhood is often associated with shadows of life threatening dangers to the mother and the unborn child, even though pregnancy and childbirth is purely a physiological process.

Pre-eclampsia is one of the complication of pregnancy and contributes significantly maternal as well as perinatal morbidity and mortality ${ }^{(1,2)}$. This disorder is characterised by involvement of cardiovascular, coagulation, renal and hepatic system ${ }^{(3,4)}$. This is a life threatening complication of pregnancy and is characterised by high blood pressure and proteinuria ${ }^{(5)}$.

Extensive studies have been made to detect the aetiology and pathogenesis of the condition. But despite decade of research, the aetiology of PIH has remained elusive and no definite and universally accepted conclusion has been reached ${ }^{(6)}$. During normal pregnancy, renal blood flow and glomerular filtration increases appreciably. With the development of preeclampsia renal perfusion and glomerular filtration are reduced, resulting in impairment of renal function. The main characteristic feature of pre-eclampsia i.e. edema, proteinuria and hypertension are due to renal involvement. There occurs renal vasospasm which eventually produce endothelial damage, proteinuria and hypertension $^{(7,8,9)}$.

So considering the mater related to our country an attempt has been made to study the incidence of preeclampsia in relation to age of the mother. The purpose of the study is to show the relationship if exists between maternal age and chances of risk of pre-eclampsia to help early detection of pre-eclampsia.

\section{Aim}

To study what age group is more prone for the development of pre-eclampsia in normal pregnancies. 


\section{Methodology}

The present study was a cross sectional study undertaken from $1^{\text {st }}$ August 2017 to $1^{\text {st }}$ August 2019. Cases were collected from the department of Obstetric and Gynaecology, Silchar Medical College and Hospital, Silchar.

400 pre-eclamptic women in the age group $18-$ 42 years were included in the study. Cases are divided according to different age group 18-26 years, 27-34 years and $35-42$ years.

Criteria for selection of cases -400 pre-eclamptic women in the age group $18-42$ years were taken as cases. The pre-eclamptic women were diagnosed in accordance with American College of Obstetric and Gynaecology guidelines.

MILD PRE-ECLAMPSIA - SBP $>140 \mathrm{mmHg}$ and DBP $>90 \mathrm{mmHg}$ on two separate readings four hours apart and proteinuria $(1+/ 2+)$ on dipstick measurement.

SEVERE PRE-ECLAMPSIA - SBP $>160 \mathrm{mmHg}$ and DBP $>110 \mathrm{mmHg}$ on two separate readings four hours apart and proteinuria $(\geq 3+)$ on dipstick measurement.

Exclusion Criteria - Pre-eclamptic patients with history of having hypertension, cardiovascular disease, renal disease, hepatic disease, endocrine or metabolic disorder before the onset of the present pregnancy are excluded from taking as cases.

\section{Result -}

Table 1 showing age wise distribution of pregnant women with pre-eclampsia.

\begin{tabular}{|l|l|l|}
\hline $\begin{array}{l}\text { Age group in } \\
\text { years }\end{array}$ & $\begin{array}{l}\text { Number of pregnant women with pre- } \\
\text { eclampsia }\end{array}$ & \% of pregnant women with pre-eclampsia \\
\hline $18-26$ & 188 & 47 \\
\hline $27-34$ & 40 & 10 \\
\hline $35-42$ & 172 & 43 \\
\hline Total & 400 & 100 \\
\hline
\end{tabular}

The above table showed incidence of pre-eclampsia $47 \%$ in age group $18-26$ years; $12 \%$ in age group $27-34$ years; $43 \%$ in age group $35-42$ years.

Table 2 showing comparison of percentage of cases of pre-eclampsia among age groups 18-26 yrs and 27-34 yrs.

\begin{tabular}{|l|l|l|l|}
\hline parameter & $\begin{array}{c}\text { Age (yrs) } \\
\mathbf{1 8 - 2 6}\end{array}$ & $\begin{array}{l}\text { Age (yrs) } \\
\mathbf{2 7 - 3 4}\end{array}$ & significance \\
\hline$\%$ of cases of preeclampsia & $47 \%$ & $10 \%$ & $<0.05$ \\
\hline
\end{tabular}

Student's t-test had been applied to assess if there was any significance difference in percentage pre-eclampsia cases in age group 18-26 yrs and 27-34 yrs. It had been observed that significant difference in percentage preeclampsia cases in age group 18-26 yrs and 27-34 yrs. 
Table 3 showing comparison of percentage of cases of pre-eclampsia among age groups 35-42 yrs and 27-34

yrs.

\begin{tabular}{|l|l|l|l|}
\hline parameter & $\begin{array}{c}\text { Age (yrs) } \\
\mathbf{3 5 - 4 2}\end{array}$ & $\begin{array}{l}\text { Age (yrs) } \\
\mathbf{2 7 - 3 4}\end{array}$ & significance \\
\hline$\%$ of cases of preeclampsia & $43 \%$ & $10 \%$ & $<0.05$ \\
\hline
\end{tabular}

Student's t-test had been applied to assess if there was any significance difference in percentage pre-eclampsia cases in age group 35-42 yrs and 27-34 yrs. It had been observed that significant difference in percentage preeclampsia cases in age group 35-42 yrs and 27-34 yrs.

Table 4 showing comparison of percentage of cases of pre-eclampsia among age groups 12-26 yrs and 35-42 yrs.

\begin{tabular}{|l|l|l|l|}
\hline parameter & $\begin{array}{l}\text { Age (yrs) } \\
\mathbf{1 8 - 2 6}\end{array}$ & $\begin{array}{l}\text { Age (yrs) } \\
\mathbf{3 5 - 4 2}\end{array}$ & significance \\
\hline$\%$ of cases of preeclampsia & $47 \%$ & $43 \%$ & $>0.05$ \\
\hline
\end{tabular}

Student's t-test had been applied to assess if there was any significance difference in percentage preeclampsia cases in age group 18-26 yrs and 35-42 yrs. It had been observed that insignificant difference in percentage pre-eclampsia cases in age group 18-26 yrs and 35-42 yrs.

\section{Discussion}

In the present study age is found related to preeclampsia. In this study highest incidence of preeclampsia is observed in the age group 18-26 years (47\%) followed by $35-42$ years $(43 \%)$.

Samuel et al found the highest incidence in the age group 16-27 years ${ }^{(10)}$. Entman et. al found the highest incidence in the age group 16-25 years ${ }^{(11)}$. Sheraj et al found pre-eclampsia more frequent with age group less than 21 years and in older age group greater than 35 years ${ }^{(12)}$. Zibaeenazhad et al reported that young primigravida less than 20 years and all patients above 30 years have an increase chance of hypertension ${ }^{(13)}$. Kumar et al documented that pregnant women less than 20 years were 3.87 times at risk of developing pre-eclampsia compared to age more than 20 years ${ }^{(14)}$. Duckill et al also observed teenage pregnancy and pregnancy above 30 years to be one of the risk factor of pre-eclampsia ${ }^{(15)}$. Sajith et al also reported that highest incidence of pre- eclampsia in the age group $18-22$ years $(41.3 \%)^{(16)}$. Walker reported that factors influencing the development of pre-eclampsia before 20 years of age may be due to initial tropoblastic invasion and how mother reacts to it. He added that failure of normal invasion tropoblastic cells leads to mal adaptation of spiral arterioles which are related to causation of pre-eclampsia ${ }^{(17)}$. Duckitt et al reported that increases incidence of pre-eclampsia in women greater than 30 years seems to be due to increases villous reaction ${ }^{(15)}$.

\section{Conclusion}

From this study, this can be concluded that maternal age less than 25 years and greater than 35 years are more prone for development of pre-eclampsia.

Source of Funding - Self

Conflict of Interest - Nil

Ethical Clearance is not required and funding within the manuscript.

\section{References}

1. Sheehan IIL and Lynch P Pathology of Toxaemia of pregnancy, Churchull Livingstone, London 1973. 
2. Chessley, L.C, Hypertensive disorder in pregnancy, Appleton-Century-Croft, New York, 1978.

3. Banner, J, Me Nicol, G.P and Dougla, A.S. Brit Med, J.2:12, 1971.

4. Dunlop W Hill Lm, London MJ Oxley and Junes P. Lancet, 2, 316, 1978.

5. Loudon I. Some historical aspects of toxaemia of pregnancy. A review. Br J Obstet Gynaecol 1991; 98-853-858.

6. Pralhod Kushlag; et al. Journal of Obstet \& Gynaecol. Of India, Feb 1993 vol. 43; No. 7: p 33.

7. Friedman SA, Taylor RN, Robert JN, Pathophysiology of pre-eclampsia Clin. Perinatol 1991;18:661-682

8. Robert J, Taylor R, GoldfienA, Endothelial cell activation as a Pathogenetic factor in pre-eclampsia. Semin Perinatol 1991; 15:86-93.

9. Zeeman GG, Dekker GA. Pathogenesis of preeclampsia hypothesis. Clin Obstet Gynecol 1992; 35:317-337.

10. Samuel, $P$ et al 1987; The origin of increases serum iron in pregnancy induced hypertension. AmJ Obst \& Gynae $157 ; 721-725$
11. Entman S.S et al 1982; Elevated serum iron in toxaemia of pregnancy. AmJ Obst \& Gynae 143:4.

12. Sheraz S, Shahzad S, Boota M. Eclampsia. Professional Medical Journal. 2006;13(1):27-31.

13. Zibaeenazhad MJ, M Ghodsi, P Arab, Gholzom $\mathrm{N}$. The prevalence of hypertensive disorders of pregnancy in Shiraz, Southern Iran. Iranian Cardiovascular Research Journal.2010;4:169-72.

14. Kumar R, Gandhi S, Rao V. Socio-Demographic and Other Risk Factors of Pre Eclampsia at a Tertiary Care Hospital, Karnataka: Case Control Study. Journal of Clinical and Diagnostic Research.2014;8(9):1-4.

15. Duckitt K, Harrington D. Risk factors for preeclampsia at antenatal booking: systematic review of controlled studies. BMJ.2005;330:56577.

16. Sajith M, Nimbargi V, Modi A, Sumariya R, Pawar A. International journal of pharma sciences and research. 2014;5(4):163-70.

17. Walker J. Baillieres best Pract Res Clin Obstet Gynaecol.2000; 57-71. 